\title{
Evaluation of a collaborator objective structured clinical examination (COSCE) in postgraduate medical education
}

\author{
V. R. Curran ${ }^{1}$, A. Reid ${ }^{2}$, H. Coombs ${ }^{1}$, P. Pike C J Farrell $^{3}$, \\ I. McPherson ${ }^{3}$, J. O'Dea ${ }^{4}$, B. Curtis ${ }^{3} \&$ J. Trahey
}

\begin{abstract}
Introduction: Effective intra- and interprofessional collaboration abilities are necessary for safe and effective medical care, however such roles are often informally taught in postgraduate medical education, with lack of opportunity for practice and feedback. The objective structured clinical examination (OSCE) is a common approach in medical education. Adaptations of the OSCE have been found useful in the assessment of collaborator competencies amongst interprofessional student groups and in the assessment of intrinsic roles, such as collaboration.
\end{abstract}

Objective: The purpose of this study was to evaluate the effectiveness of a collaborator objective structured clinical examination (COSCE) as a method of formative assessment of collaborator competencies for postgraduate trainees.

Methods: This study involved a one-group pretest-posttest evaluation conducted in 2018. Postgraduate year-1 (PGY1) residents completed a team skills scale immediately before and after COSCE participation and an evaluation survey to report satisfaction, and were assessed by facilitators and peer assessors using a COSCE rubric.

Results: Residents reported significant improvement in their pre $(n=35)$ to post ( $n=37$ ) team skills scores and an overall positive level of satisfaction with the COSCE experience ( $n=37 / 39,94.9 \%$ response rate). The lowest performance scores across all COSCE stations were transfer of care skills (e.g., handover). Peer assessor $(n=204)$ and facilitator $(n=47)$ scores indicated a moderate level of interrelatedness.

\footnotetext{
1 Office of Professional and Educational Development, Faculty of Medicine, Memorial University, St. John's, Canada

2 Centre for Collaborative Health Professional Education, Faculty of Medicine, Memorial University, St. John's, Canada

Discipline of Medicine, Faculty of Medicine, Memorial University, St. John's, Canada

4 Discipline of Paediatrics, Faculty of Medicine, Memorial University, St. John's, Canada
}

\section{Correspondence}

Vernon Curran, $\mathrm{PhD}$

Associate Dean of Educational Development

Office of Professional and Educational Development

Faculty of Medicine, Memorial University

Health Sciences Centre, Room H2982

St. John's, Newfoundland and Labrador A1B 3V6

Canada

Tel: +1 7098643346

Email: vcurran@mun.ca 
Conclusion: A COSCE is a feasible method of formative assessment, fostering role understanding of other health professions and providing feedback on collaborator skills early in postgraduate medical education. Peer assessment may also hold promise as a formative assessment method for intra- and interprofessional collaboration.

Keywords: interprofessional education; collaborator; formative assessment

\section{Introduction}

In Canada, collaboration is one of seven integrated competencies highlighted in the CanMEDS Physician Competency Framework, on which all postgraduate residency programs are based (Frank et al., 2015). The "collaborator" role is described as working effectively with other healthcare professionals to provide safe, high-quality, patientcentred care. Collaboration requires relationships based on trust, respect and shared decision making, and involves sharing perspectives and responsibilities. Altogether, effective collaboration requires understanding the roles of others, pursuing common goals and outcomes and managing differences (Royal College of Physicians and Surgeons of Canada, 2021). The CanMEDS competencies serve as a guiding framework for training and assessment in postgraduate medical education in Canada. However, faculty often feel unprepared to effectively model collaboration, and they are dissatisfied with current methods of addressing such intrinsic competencies (Berger et al., 2012; Dwyer et al., 2014; Puddester et al., 2015; Warren et al., 2014; Zabar et al., 2016).

Objective structured clinical examinations (OSCEs) are commonly used in medical education and have proven useful in the assessment of collaborator abilities among health professional students and, at a postgraduate medical education level, in assessing nonmedical expert roles, such as interprofessional collaborative practice skills, handover communication, telephone management, quality improvement and patient safety (Chander et al., 2009; Dwyer et al., 2014; Jefferies et al., 2007; Varkey \& Natt, 2007; Williams et al., 2011; Wolff et al., 2015; Zabar et al., 2016). A number of authors have described adaptations of the OSCE for assessing interprofessional collaborative skills of mixed learner groups, including medical students and physicians (Barrington, 1998; Biran, 1991; Elliot et al., 1994; Singleton et al., 1999; Symonds et al., 2003).

Zabar et al. (2016) found that OSCE cases designed to assess physician-nurse collaboration were effective in identifying deficits in interprofessional collaboration skills, and Jeffries et al. (2007) observed that residents were satisfied with the realism of a series of OSCE stations on the collaborator role. Elliot et al. (1994) and Singleton et al. (1999) found a team or group OSCE (TOSCE or GOSCE) a valid and reliable method of assessment, and several authors have reported on the effectiveness of the interprofessional TOSCE (ITOSCE) as a method for formative assessment of interprofessional groups of medical students and nursing and allied health learners (Hall et al., 2011; Solomon et al., 2011; Symonds et al., 2003). 
We sought to evaluate a new Collaborator-OSCE (COSCE) as a method for providing formative feedback to junior postgraduate medical trainees on the collaborator role.

\section{Methods}

The COSCE was organized for postgraduate year-1 (PGY1) residents from anaesthesia, family medicine, medicine, paediatrics, psychiatry and surgery during the 2018 academic year. It was developed by a committee of clinical faculty members, senior resident coordinators and education specialists involved in postgraduate medical education and was administered during a required postgraduate academic half-day. The COSCE consisted of seven stations based on common scenarios involving collaboration (Table 1). These scenarios were developed through committee meetings, the practice experiences of the case developers and a review of collaboration assessment materials published in the literature (Frank et al., 2015). Each station represented a different professional task that residents might encounter while on duty, which required demonstration of knowledge, skills and/ or abilities pertaining to intra- or interprofessional collaboration. The scenarios were mapped to an appropriate competency representing the collaborator role of the CanMEDS framework (Frank et al., 2015).

The COSCE was administered to several groups of at least seven residents, and each group rotated through each 15-minute station. Each resident had the opportunity to be the "participant" in a station, while the other group members (peers) observed and conducted a peer assessment. A "facilitator" (faculty member) was assigned to each station to oversee, observe and lead a debriefing session with each group. Several of the COSCE stations involved actors from our standardised patient (SP) program, who portrayed either health professionals, patients or family members, depending on the scenario. Each station involved a tailored set of instructions for the residents along with a separate, more detailed set for the facilitators who would be leading the station. Additional materials, such as patient charts, chairs, screens or tables were provided for each station respective to the scenarios to be enacted.

On the day of the COSCE, residents assembled for an introductory lecture outlining the CanMEDS collaborator competencies and were invited to complete a pre-COSCE Team Skills Scale (TSS). Residents were assigned to one of seven groups, and each group rotated through each station. The stations were designed such that the participant of each group completed the tasks set forth in the instructions, while the peers observed and assessed the participant's demonstration of the collaborator competencies. A facilitator at each station observed and assessed residents. After each station, the SP, peers and facilitator debriefed and discussed the scenario, and the peers and facilitator completed their competency assessment forms. Upon conclusion, residents completed the post-COSCE version of the TSS, and all participants completed post-COSCE evaluation surveys. 


\section{EVALUATION OF A COSCE IN POSTGRADUATE MEDICAL EDUCATION}

\section{Table 1}

Pilot COSCE Station Names, Topics and Related Collaborator Competencies

\begin{tabular}{|c|c|c|}
\hline Station & Description/Goal & Competencies* \\
\hline 1. Patient discharge & $\begin{array}{l}\text { This station involves a disagreement between allied } \\
\text { health (charge nurse) and attending medical staff } \\
\text { (postgraduate trainee) about discharge planning. }\end{array}$ & $1.1,1.2,1.3,2.1,2.2$ \\
\hline $\begin{array}{l}\text { 2. Collaborative } \\
\text { care plan }\end{array}$ & $\begin{array}{l}\text { The resident is expected to provide a patient case } \\
\text { presentation and develop a medical and surgical } \\
\text { management plan that recognises the roles of other } \\
\text { health professionals involved in optimal collaborative } \\
\text { care of the patient. }\end{array}$ & $1.1,1.2,1.3$ \\
\hline $\begin{array}{l}\text { 3. Shared decision } \\
\text { making }\end{array}$ & $\begin{array}{l}\text { Two-part station-first, manage conflict with, and } \\
\text { counsel, a senior resident colleague who has } \\
\text { mismanaged a patient in the ER due to fatigue; } \\
\text { second, engage in shared decision making on how } \\
\text { to manage the patient. }\end{array}$ & $1.3,2.1,2.2$ \\
\hline 4. Patient transfer & $\begin{array}{l}\text { The purpose of this station is to engage the learner } \\
\text { in considering the services that allied health } \\
\text { professionals provide and to determine which of these } \\
\text { services should be involved in their patient's care. }\end{array}$ & $1.2,3.1$ \\
\hline 5. Disclosure & $\begin{array}{l}\text { This station requires the learner to develop a } \\
\text { disclosure plan for a medication error. The learner } \\
\text { will demonstrate an ability to disclose an adverse } \\
\text { event to an authority and negotiate a disclosure plan } \\
\text { that includes the patient, nursing staff and attending } \\
\text { medical staff. }\end{array}$ & 1.1., 1.3 \\
\hline $\begin{array}{l}\text { 6. Caregiver } \\
\text { discussion }\end{array}$ & $\begin{array}{l}\text { This station involves a discussion between the } \\
\text { resident and adult child of an elderly patient. The } \\
\text { purpose of this station is for the learner to listen } \\
\text { attentively to the caregiver concerns regarding their } \\
\text { parent, identify the issues and provide advice/plan } \\
\text { to address the concerns. This will require the learner } \\
\text { to have insight into their role on the healthcare team } \\
\text { and the role of other healthcare professionals. }\end{array}$ & $1.2,1.3,3.1,3.2$ \\
\hline 7. Handover & $\begin{array}{l}\text { This station involves the assessment of handover of } \\
\text { patient care between an on-call night resident and a } \\
\text { daytime resident. }\end{array}$ & $3.1,3.2$ \\
\hline
\end{tabular}

\section{* CanMEDS: Collaborator key and enabling competencies}

1. Work effectively with physicians and other colleagues in the healthcare professions

1.1 Establish and maintain positive relationships with physicians and other colleagues in the healthcare professions to support relationship-centred collaborative care

1.2 Negotiate overlapping and shared responsibilities with physicians and other colleagues in the healthcare professions in episodic and ongoing care 


\section{EVALUATION OF A COSCE IN POSTGRADUATE MEDICAL EDUCATION}

1.3 Engage in respectful shared decision making with physicians and other colleagues in the healthcare professions

2. Work with physicians and other colleagues in the healthcare professions to promote understanding, manage differences and resolve conflicts

\subsection{Show respect toward collaborators}

2.2 Implement strategies to promote understanding, manage differences and resolve conflicts in a manner that supports a collaborative culture

3. Hand over the care of a patient to another healthcare professional to facilitate continuity of safe patient care

3.1 Determine when care should be transferred to another physician or healthcare professional

3.2 Demonstrate safe handover of care, using both verbal and written communication, during a patient transition to a different healthcare professional, setting or stage of care

We followed a one-group, pretest-posttest evaluation study design that measured change in perceptions of abilities to collaborate in a health/social care team setting, with residents completing the TSS immediately before and after COSCE participation. The TSS was an adapted version of one originally developed by Hepburn et al. (2002). It included 13 teambased task items, and respondents were asked to rate the extent to which they possess the ability to carry out each task on a 5-point scale, where $1=$ poor and $5=$ excellent . Residents were also asked to evaluate their satisfaction with the COSCE experience using an evaluation survey adapted from Hall et al. (2011), which included nine statements to which respondents rated agreement on a 5-point Likert scale, where 1 = strongly disagree and 5 = strongly agree. Residents were also asked to rank the usefulness of the seven stations and were invited to provide open-ended feedback about what they learned from the COSCE, how the COSCE could be improved and what, if any, concepts or situations were missing from the stations.

Peer assessors and facilitators used a rubric adapted from the Royal College of Physicians and Surgeons of Canada (Glover et al., 2015) to assess collaborator competencies. The rubric included five competency statements reflecting the CanMEDS collaborator role: effective teamwork, team communication, collaboration along patient care continuum, handover and management of differences and conflict, as well as a global rating of overall performance in the respective station (Frank et al., 2015). Assessors rated performance on each competency using a scale where $1=$ well below expected and $5=$ well above expected .

We analysed the TSS scores, assessment ratings and COSCE feedback forms using IBM SPSS Statistics 23. We compared resident mean scores on the pre-/post-COSCE TSS using independent samples t-tests to evaluate the effect of the COSCE on self-perceived skills as collaborative team members. Assessment scores from each resident team allowed for means comparisons between teams and stations using one-way ANOVAs. Comparison of 


\section{EVALUATION OF A COSCE IN POSTGRADUATE MEDICAL EDUCATION}

mean assessment ratings between residents and observers was performed using independent samples t-tests. We analysed the reliability of the COSCE stations by calculating Cronbach's alpha coefficients for each measure and intraclass correlation coefficients within each station and resident team. In addition, we assessed the overall amount of agreement between observer and resident assessment ratings by calculating point-biserial correlation coefficients.

\section{Table 2}

Residents' Team Skills Scale Item Mean Responses, Pre- and Post-COSCE

\begin{tabular}{|c|c|c|c|c|}
\hline \multirow{2}{*}{ TSS Item } & \multicolumn{2}{|c|}{ Pre-COSCE } & \multicolumn{2}{|c|}{ Post-COSCE } \\
\hline & $\mathbf{n}$ & Mean (SD) & $\mathbf{n}$ & Mean (SD) \\
\hline 1. Function effectively in an interprofessional team & 35 & $3.23(0.81)$ & 37 & $3.51(0.77)$ \\
\hline 2. Treat interprofessional team members as colleagues & 35 & $3.51(0.89)$ & 37 & $3.65(0.79)$ \\
\hline $\begin{array}{l}\text { 3. Identify contributions to patient/client care that different } \\
\text { professions can offer }\end{array}$ & 35 & $3.09(0.61)$ & 37 & $3.41(0.64)$ \\
\hline $\begin{array}{l}\text { 4. Apply your clinical knowledge for the care of patients/ } \\
\text { clients and/or family in an interprofessional team } \\
\text { care setting }\end{array}$ & 35 & $3.06(0.54)$ & 37 & $3.41(0.60)$ \\
\hline $\begin{array}{l}\text { 5. Ensure that patient/family preferences/goals are } \\
\text { considered when developing the team's care plan }\end{array}$ & 35 & $3.20(0.72)$ & 37 & $3.46(0.65)$ \\
\hline 6. Handle disagreements effectively & 35 & $2.83(0.79)$ & 37 & $3.27(0.56)$ \\
\hline 7. Strengthen cooperation among professions & 34 & $2.94(0.69)$ & 37 & $3.38(0.72)$ \\
\hline $\begin{array}{l}\text { 8. Carry out responsibilities specific to the medical } \\
\text { resident's role on a team }\end{array}$ & 35 & $3.17(0.66)$ & 37 & $3.51(0.65)$ \\
\hline 9. Develop an interprofessional care plan & 35 & $2.80(0.68)$ & 37 & $3.38(0.68)$ \\
\hline 10. Adjust your care to support the team goals & 35 & $3.03(0.66)$ & 37 & $3.46(0.69)$ \\
\hline $\begin{array}{l}\text { 11. Develop intervention strategies that help patients/ } \\
\text { clients attain goals }\end{array}$ & 35 & $2.97(0.66)$ & 37 & $3.41(0.69)$ \\
\hline 12. Recognize when the team is not functioning well & 35 & $3.14(0.60)$ & 37 & $3.32(0.63)$ \\
\hline 13. Intervene effectively to improve team functioning & 35 & $2.71(0.67)$ & 37 & $3.32(0.78)$ \\
\hline TSS Mean Score * & 35 & $3.05(0.55)$ & 37 & $3.42(0.59)$ \\
\hline
\end{tabular}




\section{EVALUATION OF A COSCE IN POSTGRADUATE MEDICAL EDUCATION}

The evaluation study was approved by the Newfoundland and Labrador Health Research Ethics Board.

\section{Results}

Thirty-nine residents, seven facilitators and seven standardised patients (SPs) took part in the COSCE activity. When we compared residents' TSS results at pre- $(n=35)$ and post- $(n=37)$ COSCE intervals, we found the internal consistency of the scale was excellent at both intervals ( $\alpha=0.95$ and 0.97 , respectively). The mean responses for each TSS item are outlined in Table 2 . An independent samples t-test indicated a significant difference in pre- and post-TSS scores $(t=2.75 ; p<.01)$ and a moderately strong observed effect size (Cohen's $d=0.68$ ) between the overall mean pre- $(M=3.05)$ and post-TSS scores $(M=3.42)$.

The COSCE assessment ratings indicated a high level of internal consistency, with a Cronbach's alpha value of $\alpha=0.96$. Table 3 summarises the overall mean assessment scores of both peer assessors ( $n=116$ to 204$)$ and facilitators $(n=14$ to 47$)$ on each of the CanMEDs collaborator competencies across all COSCE stations. Generally, the overall mean assessment scores of facilitators appeared lower than those of the peer assessors. However, only one competency, "effective teamwork", indicated a significant difference $(t=-2.51 ; p<.05)$ between peer assessor and facilitator scores.

\section{Table 3}

Mean COSCE Assessment Rubric Scores for Peer Assessors and Facilitators

\begin{tabular}{|c|c|c|c|c|c|c|c|}
\hline \multirow[t]{2}{*}{ Collaborator Competency } & \multicolumn{3}{|c|}{$\begin{array}{l}\text { Peer Assessors } \\
\text { (Residents) }\end{array}$} & \multicolumn{3}{|c|}{ Facilitators } & \multirow[t]{2}{*}{ Significance } \\
\hline & $\mathbf{n}$ & Mean & SD & $\mathbf{n}$ & Mean & SD & \\
\hline Effective teamwork & 204 & 4.18 & 0.63 & 47 & 3.91 & 0.69 & $t_{(249)}=-2.51 ; p=.013$ * \\
\hline Team communication & 212 & 4.13 & 0.75 & 47 & 3.94 & 0.73 & $t_{(257)}=-1.19 ; p=.235$ \\
\hline $\begin{array}{l}\text { Collaboration along patient } \\
\text { continuum }\end{array}$ & 201 & 4.15 & 0.70 & 40 & 4.08 & 0.86 & $t_{(239)}=-0.35 ; p=.724$ \\
\hline Handover & 116 & 4.12 & 0.71 & 14 & 3.79 & 0.70 & $t_{(128)}=-1.63 ; p=.105$ \\
\hline $\begin{array}{l}\text { Management of difference } \\
\text { and conflict }\end{array}$ & 166 & 4.30 & 0.74 & 27 & 3.96 & 0.85 & $t_{(191)}=-1.84 ; p=.067$ \\
\hline $\begin{array}{l}\text { Global collaborator } \\
\text { competency }\end{array}$ & 184 & 3.92 & 0.76 & 44 & 3.70 & 0.85 & $t_{(226)}=-1.35 ; p=.179$ \\
\hline
\end{tabular}

* statistically significant difference, $p<.05$

To examine whether or not a standardised COSCE would enable consistent resident competency demonstrations across all stations, we combined assessment ratings from both 


\section{EVALUATION OF A COSCE IN POSTGRADUATE MEDICAL EDUCATION}

facilitators and peer assessors and compared them across stations using a one-way ANOVA. This analysis revealed a significant difference among mean assessment scores $(\mathrm{F}(6,263)=$ $3.40 ; p<.01)$. Overall COSCE scores are presented in Figure 1. Post-hoc analyses using Tukey's HSD tests revealed significant differences between stations 1 and $3(p<.001)$ and 3 and $6(p<.001)$; means for stations $2,4,5$ and 7 did not differ from any other station. Participants ( $\mathrm{n}=32$ to 41 ) demonstrated lowest overall mean scores on the "transfer of care" station $(M=3.82)$.

\section{Figure 1}

Mean COSCE Assessment Scores by COSCE Station

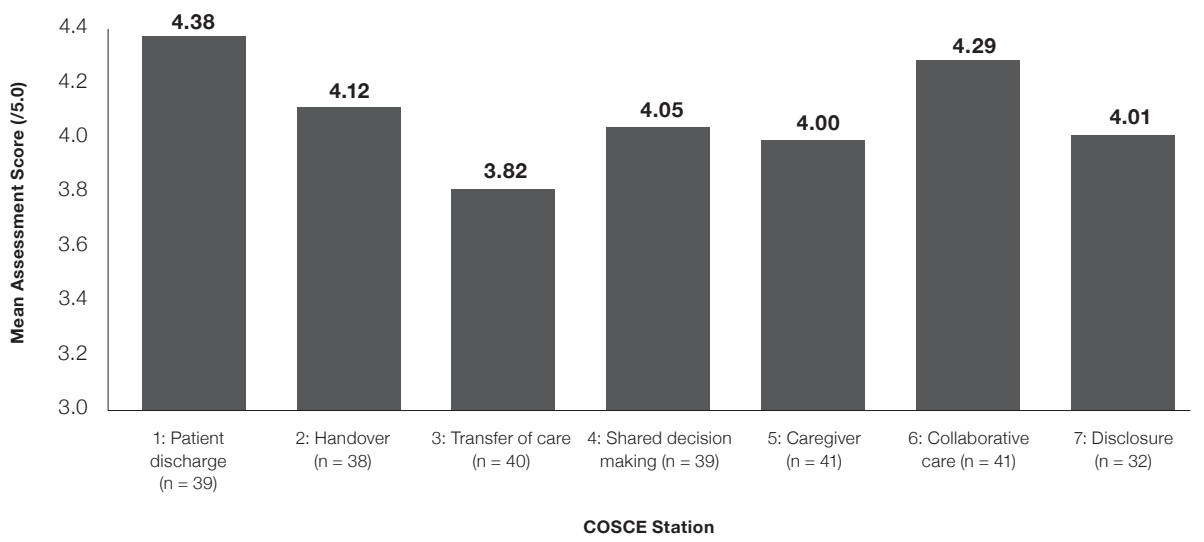

\section{Figure 2}

\section{COSCE Evaluation Survey}

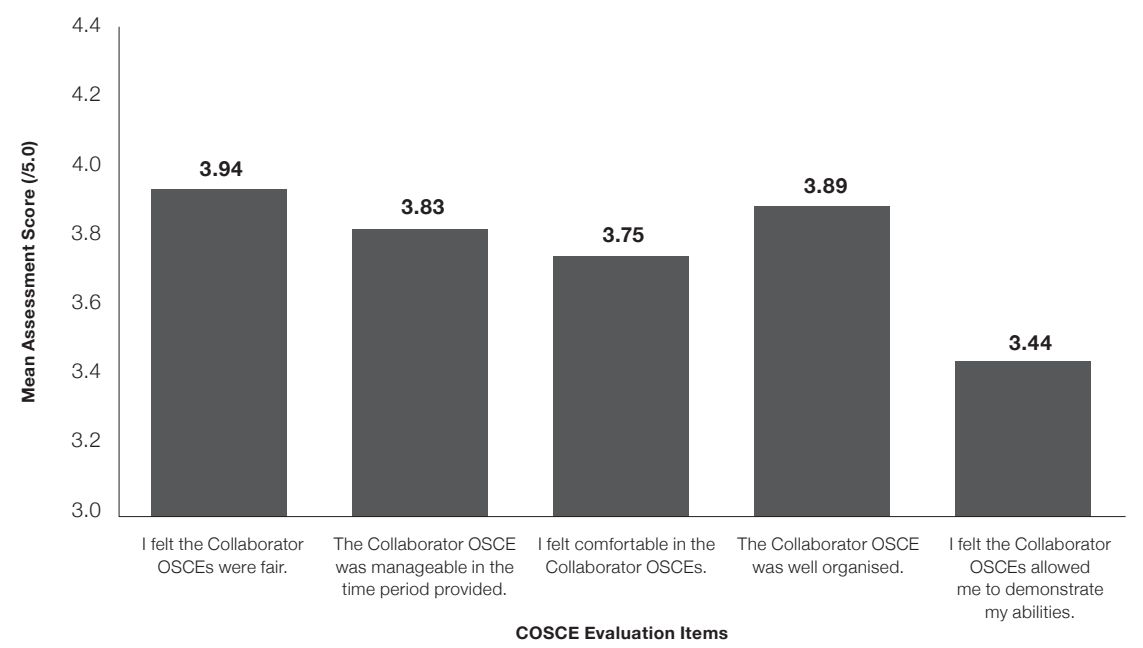


Thirty-seven of the 39 residents (94.9\%), all seven facilitators (100\%) and all seven standardised patients (100\%) who attended the COSCE exercise submitted an evaluation survey. Figure 2 summarises mean scores for items related to satisfaction with the COSCE process. Residents reported overall positive perceptions with the logistics and process of the COSCE experience, however they were less likely to agree that all the stations were necessary or provided an opportunity to demonstrate collaborator competence. Facilitators were generally more positive about the COSCE experience and reported they felt the COSCE stations were realistic and the assessment materials enabled an acceptable assessment of resident competencies.

\section{Discussion}

Residents reported significant improvement in their self-perceived team skills following participation in the COSCE. The highest improvement in the mean scores resulted from items 13 "Intervene effectively to improve team functioning" (+0.61 increase) and 9 "Develop an interprofessional care plan" (+0.58 increase). The collaborator rubric demonstrated moderately good reliability in the assessment of collaborator competencies of postgraduate trainees in a COSCE setting. The station "Patient transfer", or "Transfer of care skills", demonstrated the lowest mean assessment scores of all COSCE stations, and the scores also demonstrated considerable variation across groups. Patient transfer has been identified as a key aspect of intra- and interprofessional collaborative care, and studies suggest that residents tend to demonstrate some deficiencies in their abilities to transfer care in an effective and safe manner (Arora et al., 2005; Lofgren et al., 1990). Many postgraduate medical education programs do not formally teach this skill, and effective teaching approaches have not been well defined (Borowitz et al., 2008; Johnson et al., 2015). Our evaluation confirms the need for improved teaching and assessment of patient transfer.

A majority of residents identified that the most important learning benefit of the COSCE was exposure to principles of intra- and interprofessional collaboration, practising communication skills and learning to handle adverse situations. Adverse situations could involve possible communication gaps or lack of information sharing between team members, which could negatively affect patient safety. In terms of improving the COSCE, residents suggested making the stations shorter, or more concise, and making them more challenging for PGY1s. Residents also wanted more information about the allied health professionals' roles in providing care in the various scenarios.

Peer assessment was integrated throughout the COSCE experience. Finn and Garner (2011) describe peer assessment as the process of having members of a group judge the extent to which their fellow group members have exhibited specific traits, behaviours or 
achievements. Peer assessment has been endorsed as a process that can foster reflection about both personal and professional qualities and is reported to be a reliable method in medical education for assessing intrinsic domains of competence, such as interpersonal skills, humanism and teamwork skills (Dannefer et al., 2005; Nofziger et al., 2010; Speyer et al., 2011). The pooled scores across teams for each station did not indicate any significant differences between peer assessors and facilitators across the majority of stations. As well, a moderate degree of interrelatedness between the overall mean COSCE ratings of all peer assessors and facilitators was indicated.

A main limitation of our evaluation is it involves a single institutional study, and we did not plan to conduct any longer-term evaluation of the impact of the COSCE on subsequent collaborator assessment outcomes later in participants' postgraduate medical education. The results of the one-group, pretest-posttest study design do indicate significant selfreported increases in team skill abilities, and the alignment of assessment scoring does suggest that peer assessment could offer potential for formative peer feedback on collaborator competency development.

\section{Conclusion}

The development of collaborator competencies among postgraduate residents is essential for safe and effective medical practice. However, the assessment of collaboration in medical education has proven challenging. Our findings suggest that a formative COSCE is a feasible method of formatively assessing and promoting the development of collaborator skills early in postgraduate medical education. Peer assessment may also hold promise as a method for providing formative feedback to postgraduate trainees on intrinsic roles such as intra- and interprofessional collaboration.

\section{Acknowledgements}

The authors wish to thank Dr Karen Downton, Ms Laura Fallon, Mr Frank McLean, Uchechukwu Manujibeya, Ms Lorna Coles and the PGY1 residents who participated in the COSCE. We would also like to thank Dr Nicholas Fairbridge for assistance in preparing this manuscript.

\section{Funding and conflicts of interest}

The authors report no conflicts of interest. The authors alone are responsible for the content and writing of the article. No funding was received for this study. 
EVALUATION OF A COSCE IN POSTGRADUATE MEDICAL EDUCATION

\section{References}

Arora, V., Johnson, J., Lovinger, D., Humphrey, H. J., \& Meltzer, D. O. (2005). Communication failures in patient sign-out and suggestions for improvement: A critical incident analysis. Quality and Safety in Health Care, 14(6), 401-407. https://doi. org/10.1136/qshc.2005.015107

Barrington, D. (1998). Student evaluation of an interactive, multidisciplinary clinical learning model. Medical Teacher, 20(6), 530-535. https://doi. org $/ 10.1080 / 01421599880238$

Berger, E. D., Chan, M., Kuper, A., Albert, M., Jenkins, D., Harrison, M., \& Harris, I. (2012). The CanMEDs role of collaborator: How is it taught and assessed according to faculty and residents? Paediatrics \& Child Health, 17(10), 557-560. https://doi. org $/ 10.1093 / \mathrm{pch} / 17.10 .557$

Biran, L. A. (1991). Self-assessment and learning through GOSCE (group objective structured clinical examination). Medical Education, 25, 475-479. https://doi. org/10.1111/j.1365-2923.1991.tb00100.x

Borowitz, S. M., Waggoner-Fountain, L. A., Bass, E. J., \& Sledd, R. M. (2008). Adequacy of information transferred at resident sign-out (inhospital handover of care): A prospective survey. Quality and Safety in Health Care, 17(1), 6-10. https://doi.org/10.1136/ qshc. 2006.019273

Chander, B., Kule, R., Baiocco, P., Chokhavatia, S., Kotler, D., Poles, M., Zabar, S., Gillespie, C., Ark, T., \& Weinshel, E. (2009). Teaching the competencies: Using objective structured clinical encounters for gastroenterology fellows. Clinical Gastroenterology and Hepatology, 7(5), 509-514. https://doi.org/10.1016/ j.cgh.2008.10.028

Dannefer, E. F., Henson, L. C., Bierer, S. B., Grady-Weliky, T. A., Meldrum, S., Nofziger, A. C., Barclay, C., \& Epstein, R. M. (2005). Peer assessment of professional competence. Medical Education, 39, 713-722. https://doi.org/10.1111/j.1365-2929.2005.02193.x

Dwyer, T., Glover, T. S., Kennedy, H. M., Herold, J., Wasserstein, D., Nousiainen, M., Ferguson, P., Wadey, V., Murnaghan, M. L., Leroux, T., Semple, J., Hodges, B., \& Ogilvie-Harris, D. (2014). How to assess communication, professionalism, collaboration and the other intrinsic CanMEDS roles in orthopedic residents: Use of an objective structured clinical examination (OSCE). Canadian Journal of Surgery, 57(4), 230-236. https://doi.org/10.1503/cjs.018813 


\section{EVALUATION OF A COSCE IN POSTGRADUATE MEDICAL EDUCATION}

Elliot, D. L., Fields, S. A., Keenen, T. L., Jaffe, A. C., \& Toffler, W. L. (1994). Use of a group objective structured clinical examination with first-year medical students. Academic Medicine, 69(12), 990-992. http://doi.org/10.1097/00001888-199412000-00018

Finn, G. M., \& Garner, J. (2011). Twelve tips for implementing a successful peer assessment. Medical Teacher, 33(6), 443-446. https://doi.org/10.3109/0142159X.2010.546909

Frank, J. R., Snell, L., \& Sherbino, J. (2015). CanMEDS 2015 Physician Competency Framework. Royal College of Physicians and Surgeons of Canada. http://canmeds. royalcollege.ca/en/framework

Glover, T. S., Abbott, C., Oswald, A., \& Frank, J. R. (2015). CanMEDS teaching and assessment tools guide. Royal College of Physicians and Surgeons of Canada.

Hall, P., Marshall, D., Weaver, L., Boyle, A., \& Taniguchi, A. (2011). A method to enhance student teams in palliative care: Piloting the McMaster-Ottawa team observed structured clinical encounter. Journal of Palliative Medicine, 14(6), 744-750. https:// doi.org/10.1089/jpm.2010.0295

Hepburn, K., Tsukuda, R. A., \& Fasser, C. (2002). Team skills scale. In G. D. Heinemann \& A. M. Zeiss (Eds.), Team performance in health care: Assessment and development (pp. 159-163). Kluwer Academic/Plenum. http://doi.org/10.1007/978-1-4615-0581-5

Jefferies, A., Simmons, B., Tabak, D., McIlroy, J. H., Lee, K. S., Roukema, H., \& Skidmore, M. (2007). Using an objective structured clinical examination (OSCE) to assess multiple physician competencies in postgraduate training. Medical Teacher, 29(2/3), 183-191. https://doi.org/10.1080/01421590701302290

Johnson, D. P., Zimmerman, K., Staples, B., McGann, K. A., Frush, K., \& Turner, D. A. (2015). Multicenter development, implementation, and patient safety impacts of a simulation-based module to teach handovers to pediatric residents. Hospital Pediatrics, 5(3), 154-158. https://doi.org/10.1542/hpeds.2014-0050

Lofgren, R. P., Gottlieb, D., Williams, R. A., \& Rich, E. C. (1990). Post-call transfer of resident responsibility. Journal of General Internal Medicine, 5(6), 501-505. https://doi. org/10.1007/BF02600880

Nofziger, A. C., Naumburg, E. H., Davis, B. J., Mooney, C. J., \& Epstein, R. M. (2010). Impact of peer assessment on the professional development of medical students: A qualitative study. Academic Medicine, 85(1), 140-147. https://doi.org/10.1097/ $\underline{\text { ACM.0b013e3181c47a5b }}$ 
Puddester, D., MacDonald, C. J., Clements, D., Gaffney, J., \& Wiesenfeld, L. (2015). Designing faculty development to support the evaluation of resident competency in the intrinsic CanMEDS roles: Practical outcomes of an assessment of program director needs. BMC Medical Education, 15, 100. https://doi.org/10.1186/s12909-015-0375-5

Royal College of Physicians and Surgeons of Canada (2021). Collaborator. Retrieved December 9, 2020, from https://www.royalcollege.ca/rcsite/canmeds/framework/ canmeds-role-collaborator-e

Singleton, A., Smith, F., Harris, T., Ross-Harper, R., \& Hilton, S. (1999). An evaluation of the team objective structured clinical examination (TOSCE). Medical Education, 33, 34-41. https://doi.org/10.1046/j.1365-2923.1999.00264.X

Solomon, P., Marshall, D., Boyle, A., Burns, S., Casimiro, L. M., Hall, P., \& Weaver, L. (2011). Establishing face and content validity of the McMaster-Ottawa team observed structured clinical encounter (TOSCE). Journal of Interprofessional Care, 25(4), 302-304. https://doi.org/10.3109/13561820.2011.571353

Speyer, R., Pilz, W., Van, D. K., \& Brunings, J. W. (2011). Reliability and validity of student peer assessment in medical education: A systematic review. Medical Teacher, 33(11), e572-e585. https://doi.org/10.3109/0142159X.2011.610835

Symonds, I., Cullen, L., \& Fraser, D. (2003). Evaluation of a formative interprofessional team objective structured clinical examination (ITOSCE): A method of shared learning in maternity education. Medical Teacher, 25(1), 38-41. https://doi. org/10.1080/0142159021000061404

Varkey, P., \& Natt, N. (2007). The objective structured clinical examination as an educational tool in patient safety. Joint Commission Journal on Quality and Patient Safety, 33(1), 48-53. https://doi.org/10.1016/s1553-7250(07)33006-7

Warren, A. E., Allen, V. M., Bergin, F., Hazelton, L., Alexiadis-Brown, P., Lightfoot, K., Mcsweeney, J., Singleton, J. F., Sargeant, J., \& Mann, K. (2014). Understanding, teaching and assessing the elements of the CanMEDS professional role: Canadian program directors' views. Medical Teacher, 36(5), 390-402. https://doi.org/10.3109/ $\underline{0142159 X .2014 .890281}$

Williams, R., Miler, R., Shah, B., Chokhavatia, S., Poles, M., Zabar, S., Gillespie, C., \& Weinshel, E. (2011). Observing handoffs and telephone management in GI fellowship training. The American Journal of Gastroenterology, 106(8), 1410-1414. https://doi. org/10.1038/ajg.2011.107 


\section{EVALUATION OF A COSCE IN POSTGRADUATE MEDICAL EDUCATION}

Wolff, M. J., Balzora, S., Poles, M., Zabar, S., Mintah, A., Wong, L., Weinshel, E., \& Malter, L. B. (2015). Objective structured clinical examination as a novel tool in inflammatory bowel disease fellowship education. Inflammatory Bowel Diseases, 21(4), 759-765. https://doi.org/10.1097/MIB.0000000000000317

Zabar, S., Adams, J., Kurland, S., Shaker-Brown, A., Porter, B., Horlick, M., Hanley, K., Altshuler, L., Kalet, A., \& Gillespie, C. (2016). Charting a key competency domain: Understanding resident physician interprofessional collaboration (IPC) skills. Journal of General Internal Medicine, 31(8), 846-853. https://doi.org/10.1007/s11606-016-3690-6 